OPEN ACCESS

Edited by:

Soo-Kyoung Choi,

Yonsei University College of Medicine

South Korea

Reviewed by:

Raquel Hernanz,

Rey Juan Carlos University, Spain

Sandra Lia Amaral,

São Paulo State University, Brazil

${ }^{*}$ Correspondence:

Youhua Wang

wangyouh@snnu.edu.cn

Specialty section

This article was submitted to

Vascular Physiology,

a section of the journal

Frontiers in Physiology

Received: 10 October 2021

Accepted: 13 January 2022

Published: 28 February 2022

Citation:

Song Y, Jia H, Hua Y, Wu C, Li S,

Li K, Liang Z and Wang Y (2022) The

Molecular Mechanism of Aerobic

Exercise Improving Vascular

Remodeling in Hypertension.

Front. Physiol. 13:792292.

doi: 10.3389/fphys.2022.792292

\section{The Molecular Mechanism of Aerobic Exercise Improving Vascular Remodeling in Hypertension}

\author{
Yinping Song ${ }^{1}$, Hao Jia ${ }^{1}$, Yijie Hua ${ }^{1}$, Chen $W^{2}{ }^{2}$, Sujuan $L^{1}{ }^{1}$, Kunzhe Li ${ }^{1}$, Zhicheng Liang ${ }^{1}$ \\ and Youhua Wang ${ }^{1 *}$
}

${ }^{1}$ Institute of Sports and Exercise Biology, School of Physical Education, Shaanxi Normal University, Xi'an, China, ${ }^{2}$ School of

Health and Sports, Xi'an Fanyi University, Xi'an, China

The treatment and prevention of hypertension has been a worldwide medical challenge.

The key pathological hallmark of hypertension is altered arterial vascular structure and function, i.e., increased peripheral vascular resistance due to vascular remodeling. The aim of this review is to elucidate the molecular mechanisms of vascular remodeling in hypertension and the protective mechanisms of aerobic exercise against vascular remodeling during the pathological process of hypertension. The main focus is on the mechanisms of oxidative stress and inflammation in the pathological condition of hypertension and vascular phenotypic transformation induced by the trilaminar structure of vascular endothelial cells, smooth muscle cells and extracellular matrix, and the peripheral adipose layer of the vasculature. To further explore the possible mechanisms by which aerobic exercise ameliorates vascular remodeling in the pathological process of hypertension through anti-proliferative, anti-inflammatory, antioxidant and thus inhibiting vascular phenotypic transformation. It provides a new perspective to reveal the intervention targets of vascular remodeling for the prevention and treatment of hypertension and its complications.

Keywords: hypertension, aerobic exercise, vascular remodeling, vascular smooth muscle cells, endothelial cells

\section{INTRODUCTION}

According to the World Health Organization (WHO), cardiovascular diseases (CVDs) are the number one cause of death worldwide. The number of deaths due to CVDs is expected to rise to approximately 23.2 million in 2030, with cardiovascular deaths accounting for $31 \%$ of all global deaths. Hypertension increases patient's risk of cardiovascular, brain, kidney, and other diseases. WHO recommends $25 \%$ relative reduction in prevalence of hypertension in public health targets by 2020 to reduce global disease burden (Diem et al., 2016). Hypertension endangers the health of the vascular system, as evidenced by vascular pathological remodeling. A characteristic pathological alteration of hypertension is augmented vasoconstrictor and attenuated vasodilator responses to various physiological stimuli, resulting in elevated vascular tone in arteries and arterioles that are exposed to persistent high blood pressure. Initially, the vascular remodeling caused by increased blood pressure allows the vasculature to adapt to short-term hemodynamic changes. However, sustained increases in blood pressure leads to chronic vascular maladaptation and dysfunction. This is manifested by structural and functional changes in the vascular endothelium, smooth muscle cells 
(VSMCs), extracellular matrix (ECM), and perivascular adipose tissue (PVAT) (Figure 1; Ghaffari et al., 2015; Wang and Khalil, 2018).

Hypertension damages blood vessels, which in turn leads to pathological changes in blood vessels-vascular remodeling. In 1994, Gibbons and Dzau introduced the concept of vascular remodeling, which is characterized by vascular dysfunction, vessel wall thickening, and increased wall-to-lumen ratio (Gibbons and Dzau, 1994). Angiotensin II (Ang II), endothelin (ET), nitric oxide (NO), local growth factors (fibroblast growth factor, platelet-derived growth factor, and transforming growth factor beta), and metalloproteinases have been shown to be closely involved in the regulation of hypertension (Brown et al., 2018). Excessive activation of the renin-angiotensin system (RAS) causes diseases such as hypertension. AngII and aldosterone levels lead to vascular fibrosis, inflammation and proliferation. The interaction of oxidative stress and inflammation also leads to vascular remodeling (Schiffrin and Touyz, 2004). United States and European hypertension guidelines encourage regular aerobic exercise in hypertensive patients because of its effectiveness in improving hypertension (Mancia et al., 2007). Aerobic exercise significantly reduces systolic 24-h blood pressure, systolic systemic vascular resistance, and small artery elasticity index (Pagonas et al., 2017). This review summarizes the molecular mechanisms of changes in vascular endothelial cells, smooth muscle cells, extracellular matrix, and vascular peripheral fat during pathological alterations. And further explored the molecular mechanism of aerobic exercise to improve vascular remodeling for the prevention and treatment of hypertension, providing a theoretical basis for the prevention and treatment of hypertension (Figure 2).

\section{ENDOTHELIAL CELLS AND THE AREOBIC EXERCISE ON VASCULAR REMODELING}

Endothelial injury is a critical early step in the development and progression of hypertension. Endothelial damage/repair imbalance causes endothelial dysfunction which in turn induces hypertension. In addition, endothelial cells (ECs) signaling disorders lead to endothelial dysfunction, which is characterized by arterial vascular remodeling (Konukoglu and Uzun, 2017).

\section{Endothelial Dysfunction}

Endothelial cells are seen as the first line of defense between risk factors and vascular disease. Endothelial cells are thought to play an important role in the regulation of local vascular tone. In 1980, Furchgott and Zawadzki (1980) discovered endotheliumderived relaxing factor (EDRF). EDRF is chemically identified as endogenous nitric oxide (NO) (Ignarro et al., 1987). Since then, endothelial dysfunction has become synonymous with reduced NO bioactivity. Furthermore, hemodynamics is ubiquitous and essential physiological stimulus for vascular cells and is thought to exert an important influence on the pathological course of hypertension by regulating endothelial cell function. Shear stress plays a role in the control of endothelial cell proliferation and apoptosis; for example, stable flow reduces EC proliferation, whereas disturbed flow increases EC turnover and stimulates apoptosis (Davies et al., 1986; Akimoto et al., 2000). An increase in shear stress usually causes vasodilation, mostly mediated by an increase in endothelial nitric oxide synthase (eNOS) activity and NO production (Rubanyi et al., 1986; Redmond et al., 1998). Indeed, shear stress is thought to be the primary physiological stimulus for this potent vasodilator molecule. Other endothelium-derived vasoactive substances altered by shear stress include PGI2 (Redmond et al., 1998; Hendrickson et al., 1999) and endothelin-1 (ET-1) (Kuchan and Frangos, 1993; Malek et al., 1993).

Hypertension is associated with endothelial dysfunction (Konukoglu and Uzun, 2017). The main factors of endothelial dysfunction are reduced bioavailability of NO, increased sensitivity of ECs to vasoconstrictors, increased production of vasoconstrictor substances and elevated shear stress (Zhou et al., 2014; Cyr et al., 2020).Bone marrow secretes and releases endothelial progenitor cells (EPCs), which migrate to the peripheral circulation and differentiate into mature vascular endothelial cells (VECs) to maintain vascular integrity. EPC levels are a risk factor for cardiovascular disease and are associated with endothelial endothelium-dependent vasodilation (Vasa et al., 2001). VECs secretes active substances such as $\mathrm{NO}$ and ET to maintain vascular homeostasis. In moderate and severe hypertension, VECs damage and imbalance of reactive substances result in decreased NO secretion, increased ET vasoconstrictor, decreased diastolic system function, and vasoconstriction (Iwakiri and Groszmann, 2007).

The nitric oxide synthase (NOS) enzyme catalyzes the eventual production of NO from L-arginine. Mammals have three NOS isoforms: neuronal (nNOS), endothelial (eNOS), and inducible (iNOS). Infection and chronic inflammation induce increased NO production by iNOS. Under hypertensive pathology, increased NO concentration generates reactive nitrogen oxides (RNOS) with oxygen radicals, which indirectly cause apoptosis and tissue damage. In contrast, eNOS, a calcium-dependent protein, has a diastolic effect. Shear stress, acetylcholine, bradykinin, and histamine stimulate eNOS activity and NO production through calcium-dependent and non-dependent way (Zhao et al., 2015). In addition, NO channels are present in the myoendothelial junction (MEJ), a cellular extension that promotes crosstalk connections between endothelial cells and vascular smooth muscle in small arteries and arterioles. eNOS expression in the MEJ limits long-distance diffusion of $\mathrm{NO}$ and reduces the scavenging of $\mathrm{NO}$ by reactive oxygen species (ROS) (Shu et al., 2019). In addition to targeting eNOS to the MEJ, hemoglobin- $\alpha(\mathrm{Hb}-\alpha)$ is enriched in the MEJ by unbiased proteomic screening. Functionally, $\mathrm{Hb}-\alpha$ acts as a "NO uptake pool" by buffering NO diffusion from endothelium to smooth muscle cells through the formation of a dioxygenation reaction between nitrate and methemoglobin$\alpha$, which further regulates NOS-mediated signaling to control vascular remodeling (Straub et al., 2012). Disruption of eNOS and $\mathrm{Hb}-\alpha$ binding with $\mathrm{Hb}-\alpha$ mimetic peptide enhances NO signaling and lowers blood pressure in vivo. Thereby identifying 


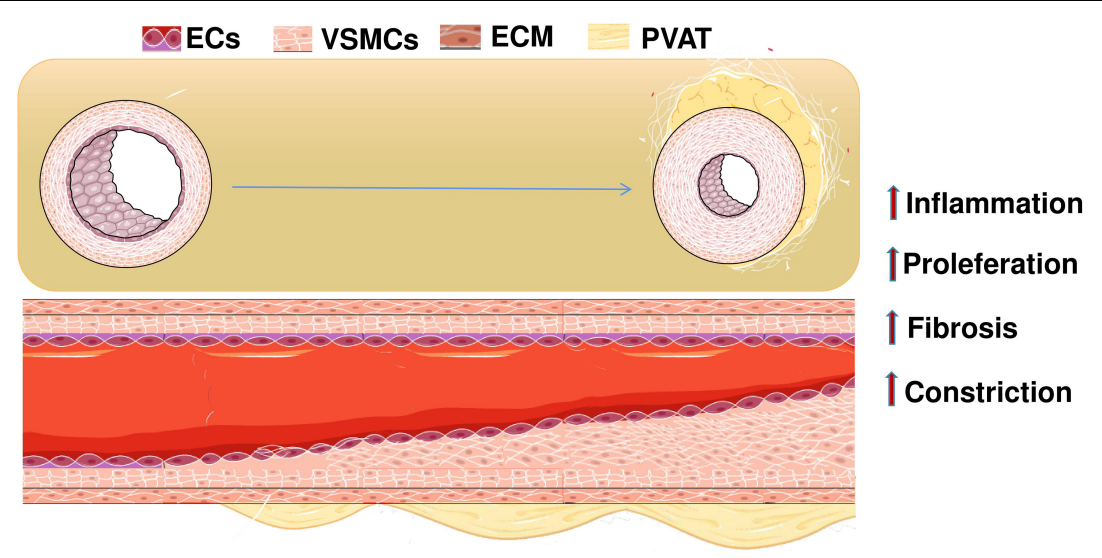

FIGURE 1 | When hypertension occurs, the continuous increase of blood pressure leads to chronic poor vascular adaptation and dysfunction. The specific manifestations are changes in the structure and function of vascular endothelial cells, smooth muscle cells, extracellular matrix, and perivascular adipose tissue. ECs, endothelial cells; VSMCs, vascular smooth muscle cells; ECM, extracellular matrix; PVAT, perivascular adipose tissue.

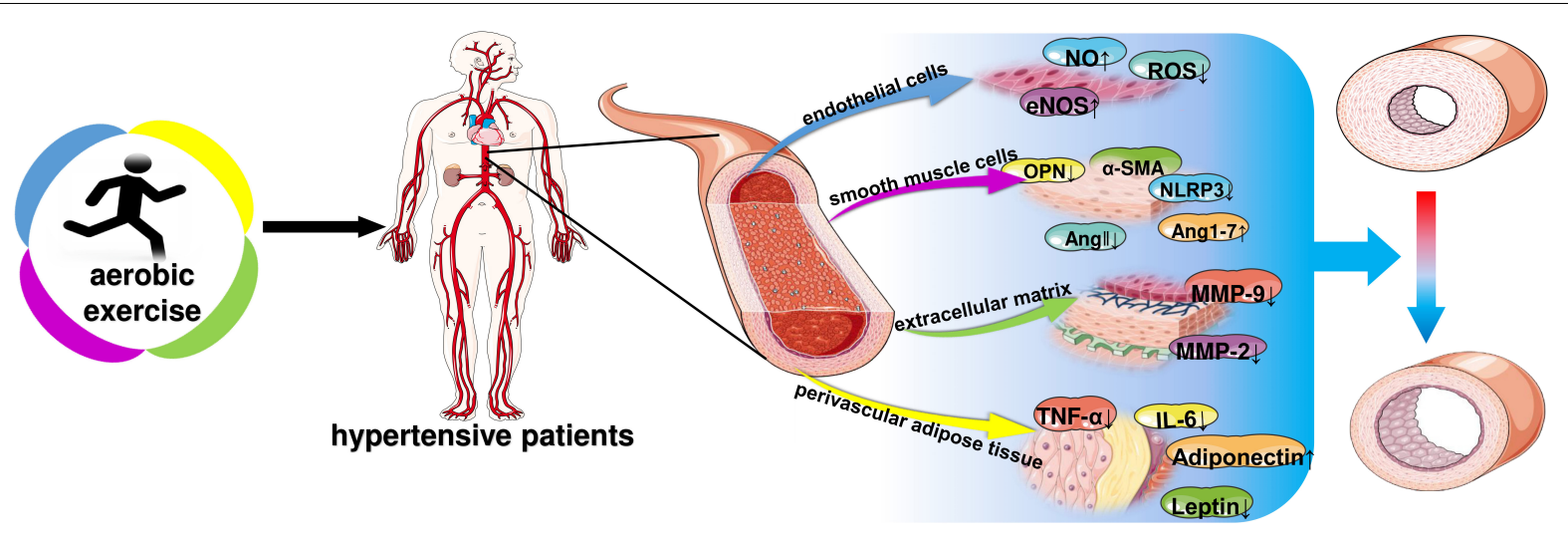

FIGURE 2 | Aerobic exercise improves molecular changes in vascular remodeling of hypertension. NO, nitric oxide; ROS, reactive oxygen species; eNOS, endothelial nitric oxide synthase; OPN, osteopontin; $\alpha$-SMA, $\alpha$-smooth muscle actin; NLRP3, NOD-like receptor thermal protein domain associated protein 3; ANG, angiotensin; MMP-9, matrix metallopeptidase 9; MMP-2, matrix metallopeptidase 2; IL-6, interleukin-6; TNF- $\alpha$, tumor necrosis factor- $\alpha$; Adiponectin; Leptin.

new targets for the treatment of hypertensive vascular remodeling (Straub et al., 2014).

\section{Reactive Oxygen Species}

Impaired endothelium-dependent vasodilatory function in hypertension is associated with oxidative stress and ROS together with other pathways reduce NO bioavailability (Virdis et al., 2013).

Reactive oxygen species alter gene expression by regulating the activation of transcription factors, with subsequent effects on downstream target proteins, and also regulate the production and degradation of extracellular matrix, inactivate NO function, and stimulate the expression of multiple kinases and proinflammatory genes (Monteiro et al., 2019).

Elevated levels of oxidative stress in hypertensive patients lead to an imbalance in the production/accumulation of ROS (Montezano et al., 2015). Nicotinamide adenine dinucleotide phosphate oxidase (Nox) is a major source of ROS in the vascular wall and has been identified as playing a key role in the pathogenesis of hypertension (Magnani and Mattevi, 2019). NOx induces increased ROS production in response to inflammation. In ECs, superoxide reacts with $\mathrm{NO}$ to generate peroxynitrite to inhibit oxidative capacity leading to oxidative stress. This further leads to vascular inflammation, fibrosis and remodeling in hypertension (Lopes et al., 2015). In addition, the mechanical forces on the vessel wall are altered in patients with hypertension. Increased stretch leads to endothelial cell proliferation and the release of Interleukin-6 (IL-6), Interleukin8 (IL-8), ROS, ET, and other pro-inflammatory mediators also contribute to impaired endothelial cell function in hypertensive vessels (Jufri et al., 2015).

\section{Aerobic Exercise Improves Vascular Remodeling Through Endothelial Cell Regulation}

The effect of aerobic exercise on the maintenance of endothelial barrier function is due to the increased heart rate, blood flow 
and shear stress associated with aerobic exercise, which in turn releases vascular protective molecules, such as NO (Laughlin et al., 2008). This immediately leads to a downregulation of endothelial angiotensin II type 1 receptor expression, which leads to a decrease in nicotinamide adenine dinucleotide phosphate (NADPH) oxidase activity and superoxide anion production, thereby reducing ROS production and maintaining endothelial NO bioavailability (Ramkhelawon et al., 2009). This ultimately allows vasodilation and slows down the vascular remodeling of the hypertensive pathological process.

Aerobic exercise for 16 weeks reduced blood pressure and promoted eNOS expression in 29-week-old rats. And exercise also reduced protein levels of insulin-like growth factor-1 (IGF-1), PI3K, and phosphorylated protein kinase B (p-Akt) (Jufri et al., 2015). Long-term aerobic exercise promotes eNOS expression and reduces hypertension via IGF-1/PI3K/p-Akt pathway (Zhang et al., 2018).

Melatonin (MT) acts as an antioxidant and anti-hypertensive. By activating melatonin receptor 2 (MT2). It can increase $\mathrm{Ca}^{2+}$ levels in endothelial cells, which in turn plays a key role in activating eNOS to increase NO production and NO bioavailability. Studies have shown that exercise can increase MT levels (Escames et al., 2012). In addition, skeletal muscle hypertrophy induced by exercise training increases the production of follicle-stimulating hormone 1 (Follistatin1, Fstl1) (Escames et al., 2012), which improves the repair of vascular endothelial cell damage and reduces the expression of inflammatory cytokines (Miyabe et al., 2014). Aerobic exercise also induces an increase in eNOS expression and thus improves vascular function by increasing shear force (Suvorava and Cortese-Krott, 2018).

\section{AEROBIC EXERCISE IMPROVES THE EFFECT OF VSMCs ON VASCULAR REMODELING}

Vascular remodeling in hypertension is manifested in the midmembrane by a shift from contractile phenotype to synthetic phenotype in VSMCs, which is a hallmark of vascular dysfunction in hypertension (Touyz et al., 2018). Multiple factors such as growth factors, ROS, and mechanical injury have been shown to be involved in VSMCs growth and phenotype conversion (Nishio and Watanabe, 1997; Luo et al., 2012; Hald and Alford, 2014).

\section{Effects of VSMC-Specific Factors and Signaling Pathway Modulation on Vascular Phenotype Transformation}

Vascular endothelium, smooth muscle cells phenotypic transition is regulated by specific factors and signaling pathways such as phosphatidylinositol kinase signaling pathway (PI3K/Akt/eNOS) and mitogen-activated protein kinase cascade reaction (MAPK). VSMC phenotypic features perform functions by virtue of different proteins, such as $\alpha$-SMA, calreticulin, smooth muscle myosin heavy chain, and SM22 $\alpha$ (Zhang et al., 2019). Osteopontin (OPN) and epithelial regulatory proteins are associated with cell growth, synthesis, proliferation, and migration (Seo et al., 2015). Vasoactive stimulation, growth factors and epidermal growth factors are involved in VSMC phenotypic conversion through activation of membrane receptors and intracellular and extracellular signaling pathways (Kennedy et al., 2016). Platelet-derived growth factor-BB (PDGF-BB) binds to PDGF receptors and subsequently activates intracellular signaling cascades such as the protein kinase B (Akt), extracellular signal-regulated kinase (ERK), and p38MAPK pathways (Chen et al., 2015). Akt is a major downstream target of phosphatidylinositol 3-kinase (PI3K). MAPK contains three major members: ERK, p38 MAPK, and c-Jun N-terminal kinase (JNK), of which ERK and p38MAPK are involved in VSMCs phenotype conversion (Ma and Wells, 2014).

\section{Inflammation Is Involved in VSMCs Phenotype Conversion}

Increased concentrations of pro-inflammatory cytokines were observed in smooth muscle cells of hypertensive patients (Chi et al., 2019). Nucleotide-binding oligomerization domain-like receptor protein 3 (NLRP3) inflammatory vesicles activate caspase- 1 and thus induce inflammation, thus becoming another new focus for triggering hypertension (Sun et al., 2017).

Nucleotide-binding oligomerization domain-like receptor protein 3 forms a complex with atypical squamous cells (ASC) prompting the conversion of procaspase- 1 to active caspase- 1 . Activated caspase- 1 prompts the conversion of pro interleukin1beta (IL-1 $\beta$ ) to mature IL-1 $\beta$ ultimately inducing inflammation. Elevated levels of the pro-inflammatory cytokine IL-1 $\beta$ in the vasculature under hypertensive pathology suggest that inflammation is highly associated with hypertensive vascular remodeling (Slaats et al., 2016). Multiple signaling and metabolic dysregulation cause NLRP3 inflammasome activation, such as $\mathrm{Ca}^{2+}$, ROS, NO, Ang II, and endoplasmic reticulum stress and mitochondrial dysfunction ( $\mathrm{He}$ et al., 2016). NLRP3 inflammasome activation leads to nuclear factor-kappaB (NF$\kappa \mathrm{B})$ signaling activation involved in the development and progression of hypertension. NLRP3 gene deletion attenuates Ang II-induced inflammation, VSMC phenotypic transformation and proliferation, and Ang II-induced hypertension and vascular remodeling (Ren et al., 2017).

\section{Renin-Angiotensin System-Induced Vascular Remodeling in Hypertension}

The renin-angiotensin system (RAS) regulates vascular tone and plays a key role in vascular remodeling (Schiffrin, 2012). The RAS consists of series of enzymatic reactions culminating in the generation of AngII in plasma as well as in cardiovascular system. The Ang II/AT1 signaling has been shown to be aberrantly activated in vascular hypertrophy and remodeling by promoting VSMC growth, transdifferentiation and proliferation, eliciting a variety of biological actions of the RAS in the vascular homeostasis (Thomas et al., 2005; Mehta and Griendling, 2007; Zhong et al., 2010; Jin et al., 2012). As a specific Ang IIdegredating enzyme, ACE2 suppresses VSMC proliferation and vascular hypertrophy. Loss of ACE2 led to vascular proliferation 
and elevated migration of SMC while ACE2 overexpression inhibited vascular proliferation and hypertrophy by preventing aortic wall thickening (Strawn et al., 1999; Landon and Inagami, 2005; Ferreira et al., 2009; Zhang et al., 2009; Zhong et al., 2011; Jin et al., 2012; Patel et al., 2012).Excessive activation of RAS under hypertensive pathology causes upregulation of the classical pathway action of the Ang-converting enzyme ACE/Ang II/Ang type I receptor (AT1R) and impairs the protective effect of the ACE2/Ang 1-7/Mas receptor (MasR) pathway.

Patients with hypertension present with locally or systemically elevated Ang II levels, i.e., excessive activation of the classical pathway. Renin released from the kidney converts angiotensinogen (AGT) produced by the liver to Ang I, which is converted to Ang II by the action of Ang converting enzyme (ACE) (Li et al., 2017). Other enzymes may also be involved in Ang II production, such as histones, chymotrypsin, etc. (Passos-Silva et al., 2013). ACE also inactivates bradykinin, which has a vasodilatory effect. The physiological effects of Ang II are mediated by the G protein-coupled receptor family, whose types are type 1 (AT1R) and type 2 (AT2R) (Zhang et al., 2017). Activation of the ACE/Ang II/AT1R pathway stimulates vasoconstriction, sympathetic activation and ROS production, and triggers harmful effects such as endothelial dysfunction, inducing vascular inflammation, thrombosis, proliferation, and fibrosis (Kawai et al., 2017). In contrast, AT2R exerts histoprotective effects, including vasodilatation, anti-inflammatory, and anti-proliferative (Santos et al., 2018).

ACE2 hydrolyzes AngI to produce Ang1-9, which is cleaved by ACE to produce Ang 1-7 (Santos et al., 2018). Ang 1-7 mainly acts through ACE2. Ang 1-7 binds to the specific receptor MasR, a $G$ protein-coupled receptor that triggers anti-inflammatory, anti-fibrotic and anti-proliferative and produces protective effects (Rodrigues Prestes et al., 2017).

\section{ROS Participates in the Phenotypic Transition of Hypertensive VSMCs}

Disruption of ROS signaling leads to the development of several diseases, such as hypertension. In hypertension, Ang II, NE, and ET-1 activate receptors located on the cell membrane, namely AT1, $\alpha$-AR, and ET receptors. These receptors are coupled to $G$ proteins and activate NADPH oxidase. Activated NADPH oxidases produce ROS, which in turn activate cellular phosphorylation pathways: MAPK, PI3K/Akt. Activated phosphorylation pathways activate transcription factors, such as activator protein-1 (AP-1), p53, NF-кB, and nuclear E2-related factor 2 (Nrf2), which promote post-entry gene transcription into the nucleus of the cell. These target genes encode proteins that subsequently mediate changes in cellular phenotypes, such as hypertrophy, inflammation, necrosis, and apoptosis (Das et al., 2018).

Although cells of different systems perform different functions, redox signaling is very similar. NADPH oxidase is a major source of ROS in endothelial cells, vascular smooth muscle cells, cardiomyocytes, renal cells, and cardiovascular neurons (Nowak et al., 2018). Ang II is an important activator of NADPH oxidase and a stimulator of ROS (Kang et al., 2019).
ROS are produced through mechanical stress stimulation of vascular smooth muscle cells, and ROS act through MAPK production to cause cell proliferation, hypertrophy and apoptosis (Gusan and Anand-Srivastava, 2013).

\section{Aerobic Exercise Improves Smooth Muscle Vascular Remodeling}

The powerful stimuli generated by aerobic exercise are associated with vascular remodeling (Green, 2009; Green et al., 2017). Small arteries are the main resistance vessels that regulate flow to different tissues of the body and control blood pressure. Phenotypic conversion of VSMC in these vessels plays an important role in structural remodeling and can lead to various cardiovascular diseases, including hypertension (Owens et al., 2004).

Exercise induced the VSMCs of SHR to maintain a more contractile phenotype, with differentiation protein $\alpha$-SM-actin and OPN, which is involved during VSMC migration and proliferation and as dedifferentiation marker being inhibited (Chaulet et al., 2001; Speer et al., 2002; Ye et al., 2009; Jiang et al., 2014).

After 8 weeks of aerobic exercise, the phenotype of spontaneously hypertensive rats was reversed, showing an increase in contractile protein expression and a decrease in synthetic protein expression. 12-week aerobic exercise increased the expression of eNOS protein in 3-month-old hypertensive rats, and decreased the expression of ERK and p38, thereby improving VSMC function. Aerobic exercise has a beneficial effect on vascular phenotyping by regulating the balance of Akt and MAPK signal pathways in VSMC. Aerobic exercise enhances the effect of PI3K/Akt/eNOS signaling pathway in normal rats, and maintains a good contractile phenotype of normal rat VSMC (Zhang et al., 2019). Aerobic exercise moves the role of RAS to the protective pathway in several disease models such as hypertension (ACE2/Ang 1-7/MasR) (Frantz et al., 2017). Eight weeks of aerobic exercise inhibits the activity of NF-кB p65, reduces the increase of norepinephrine, epinephrine and the expression of IL-1 $\beta$ and TNF- $\alpha$ in plasma (Qi et al., 2019).

Therefore, aerobic exercise is an effective intervention for hypertensive vascular remodeling. Aerobic exercise is involved in improving the vascular remodeling caused by vascular media injury in many aspects, such as reducing inflammation and activating the protective pathway of RAS from the specific signaling pathway.

\section{HYPERTENSIVE EXTRAVASCULAR MEMBRANE AND THE AMELIORATIVE EFFECT OF AEROBIC EXERCISE}

Adventitial fibroblast (AF) is the main cellular component of the adventitia of blood vessels. Under the pathology of hypertension, the ability of proliferation and migration is enhanced, and a variety of cytokines are secreted, which participates in inflammation and vascular remodeling (Qi et al., 2019). When adventitia fibroblasts are pathologically damaged, 
ECM is secreted to participate in vascular remodeling. Excessive accumulation of collagen will increase the stiffness of blood vessels and accelerate the development of hypertension. In addition, ECM induces cell signals to regulate cell adhesion, proliferation, migration, and differentiation, and participates in the remodeling of hypertensive blood vessels, among which matrix metalloproteinases (MMPs) are the key factors leading to vascular maladaptation (Castro and Tanus-Santos, 2013; Hua and Nair, 2015). Gelatinase MMP-2 and MMP-9 are vascular diseaserelated proteins, which are involved in oxidative stress and cause cardiovascular dysfunction, and are involved in vascular remodeling in chronic maladaptive hypertension (Belo et al., 2015; Han et al., 2019).

Biologically active peptides, hemodynamics and reactive oxygen species regulate the expression and activity of MMP-2. Increased MMP-2 can cause poor vascular adaptability due to hypertension (Hardy et al., 2018). MMP-2 stimulates VSMC to interact with the newly formed ECM. ECM triggers intracellular signal transduction through integrin to induce phenotypic transition and continuous migration. VSMC changes from a contractile phenotype to a synthetic phenotype, leading to vascular remodeling under the pathology of hypertension. The tissue matrix metalloproteinase inhibitor TIMP is a secreted protein that can inhibit the activity of MMPs. AF-derived TIMP1 acts on the smooth muscle cells and inflammatory cells in the vascular part through paracrine, inhibiting the enzymatic activity of MMP-9, leading to increased synthesis and secretion of collagen in blood vessels. The expression of Ang II increases during hypertension. Ang II induces the expression and secretion of type I collagen in cultured adventitia fibroblasts (Somanna et al., 2016; Fu et al., 2018). Ang II regulates the expression of MMP-2 and TIMP1 in adventitia fibroblasts, and the changes in the expression of MMP-2 and TIMP1 are involved in the secretion of collagen by adventitia fibroblasts to participate in the process of vascular remodeling.

\section{ROS Is Involved in the Regulation of Matrix Metalloproteinases}

Researches have shown that ROS can regulate the activity of MMPs. Pro-MMP-2 and pro-MMP-9 secreted by VSMC are activated by ROS (Prado et al., 2018). The expression of MMPs genes is also regulated by ROS. When VSMCs are mechanically stretched, $\mathrm{NAD}(\mathrm{P}) \mathrm{H}$ oxidase-derived ROS increases the expression of MMP-2 mRNA (Yue et al., 2018). The strategy of adjusting the bioavailability of ROS can reverse vascular remodeling, effectively prevent vascular damage and reduce hypertension and its related end-organ damage (Prado et al., 2018).

\section{Ameliorative Effect of Aerobic Exercise}

Twelve weeks of exercise training increased collagen deposition in hypertensive rats, and reduced the size of pores in the intima, which explained the beneficial effects of exercise on vascular remodeling and vasodilation, especially the pressure exerted by elastin protein at low positions. The latest research on the aorta of hypertensive rats also shows that exercise training can normalize changes in the deposition of elastic components (Moraes-Teixeira Jde et al., 2010). The imbalance between synthesis and degradation of ECM protein can affect vascular remodeling. Sports training affects the expression of MMP to varying degrees. Under pathological conditions, ROS production will increase ECM proteins, such as collagen and fibronectin (Lee and Griendling, 2008). In addition, the reduction of oxidative stress in hypertension is related to the normalization of vascular remodeling and collagen deposition observed in arteries (Zhang et al., 2016).

\section{PERIVASCULAR ADIPOSE TISSUE AND THE AMELIORATIVE EFFECT OF AEROBIC EXERCISE}

\section{PVAT Adipose Tissue Is Involved in Vascular Remodeling of Hypertension}

Perivascular adipose tissue secretes a large number of metabolically vasoactive adipokines (e.g., lipocalin, leptin, resistin, endolipin, etc.) that exert endocrine and paracrine effects (Saxton et al., 2019). Vascular injury, infection leads to abnormal PVAT and inflammatory cell infiltration and imbalance in the release of harmful and beneficial adipokines. This is usually manifested by increased levels of leptin and decreased levels of adiponectin (Zhang et al., 2016). This in turn accelerates inflammation, oxidative stress causing endothelial dysfunction and VSMC proliferation.

The adipokines produced by PVAT are more likely to cause inflammation, proliferation, and then cause vascular remodeling (Schlich et al., 2013; Nosalski and Guzik, 2017). PVAT dysfunction activates the NLRP3/IL-1 signaling pathway after early vascular injury, leading to increased proliferation and differentiation of AF, thereby aggravating vascular adventitia remodeling. PVAT causes endothelial dysfunction by increasing the oxidative stress derived from NADPH oxidase and increasing the production of pro-inflammatory adipokines (such as leptin)

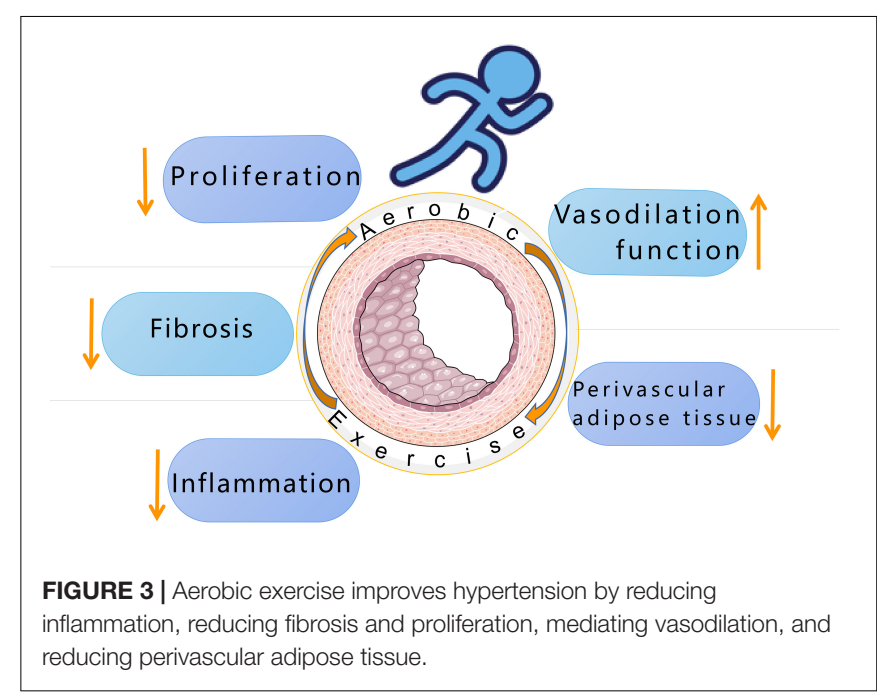


(Gil-Ortega et al., 2014). The increase of tumor necrosis factor- $\alpha$ $(\mathrm{TNF}-\alpha)$ gene expression in PVAT under hypertension is related to the increase of ET-1 and endothelin receptors. Increased TNF- $\alpha$ gene expression is related to NOS uncoupling and reduced NO release (Virdis et al., 2015). Under the pathology of hypertension, PVAT secretes a large amount of adipokines to accelerate inflammation and oxidative stress, aggravate vascular endothelial dysfunction and VSMC proliferation to accelerate vascular remodeling. Adipose tissue contains AGT and ACE, and the gene expression of AT1 receptor in PVAT is higher (Mikolajczyk et al., 2019). Systemic infusion of Ang II can cause local PVAT inflammation and participate in vascular remodeling of hypertension. Adiponectin induces AMP-activated protein kinase (AMPK) phosphorylation, inhibits the migration of mouse outer membrane fibroblasts and inhibits the expression of nitric oxide synthase (Ghantous et al., 2020).

\section{Aerobic Exercise Regulating Vascular Remodeling by Ameliorating PVAT}

Aerobic exercise can significantly reduce the serum leptin level in PVAT in patients with hypertension and improve leptin resistance, and the adiponectin content increases. Aerobic exercise can improve the low-grade inflammation in obese people and reduce the level of plasma inflammatory cytokines (Sousa et al., 2019).

The activation of endothelial cell mechanical sensors during aerobic exercise stimulates the production of eNOS and NO, reduces vascular oxidative stress, increases antioxidant response and improves NO bioavailability (Sponton et al., 2017; Ruegsegger and Booth, 2018). In addition, aerobic exercise changes the metabolic phenotype of adipose tissue and inhibits the expression of inflammatory markers (Boa et al., 2017). Aerobic exercise is beneficial to restore eNOS activation or reduce iNOS protein expression, both of which are related to the normalization of contractile vascular reactivity in obese rats (Araujo et al., 2018).

Exercise training reduces PVAT inflammation (Lee et al., 2016). Aerobic exercise training stimulates angiogenesis in adipose tissue, improves blood flow and reduces hypoxia and macrophage infiltration (You et al., 2013). It can also prevent or weaken the infiltration of immune cells into PVAT, thereby improving blood vessel function (Boa et al., 2017). At the same time, mechanical stimulation of exercise plays a basic role in preventing endothelial dysfunction by reducing ROS and increasing the bioavailability of NO. Exercise training increases the expression of eNOS protein in the aorta and prevents the upregulation of iNOS in PVAT. Aerobic exercise also increases the

\section{REFERENCES}

Akimoto, S., Mitsumata, M., Sasaguri, T., and Yoshida, Y. (2000). Laminar shear stress inhibits vascular endothelial cell proliferation by inducing cyclindependent kinase inhibitor p21(Sdi1/Cip1/Waf1). Circ. Res. 86, 185-190. doi: 10.1161/01.res.86.2.185

Araujo, H. N., Jamaira, A., Victório, Carmem, P. V. S., Amanda, C. S. S., Jean, F. V., et al. (2018). Anti-contractile effects of perivascular adipose tissue in thoracic expression of Mn-SOD protein in PVAT and reduces tissue ROS production (Huang et al., 2018).

\section{CONCLUSION}

To sum up, the pathological changes of the three-layer membrane structure of blood vessels and the increase of perivascular adipose tissue are the factors that lead to the development of hypertensive vascular remodeling. At present, clinically, antihypertensive drugs that may have a beneficial effect on vascular remodeling are being explored, such as neutral lysozyme inhibitors related to angiotensin receptor blockers, aldosterone synthase inhibitors, and renal denervation and baroreceptors Stimulate and other new drugs. In terms of exercise, it has been proven that aerobic exercise can improve vascular remodeling by improving the tunica intima, media, and adventitia thickening and fibrosis under the pathology of hypertension (Figure 3). Based on a large number of previous studies, the future research direction of aerobic exercise and hypertension can be as follows: (1) To further accurately grasp the exercise intensity and exercise time of people of different ages, races and degrees of vascular remodeling. (2) Regular aerobic exercise can reduce ROS in cells and increase the bioavailability of NO, but the mechanism of endothelial function improvement during exercise has not been fully elucidated. Or the protective effect of aerobic exercise in regulating DNA methylation on the cardiovascular system can be used as a further research direction.

\section{AUTHOR CONTRIBUTIONS}

YS wrote the manuscript. HJ and YH designed the figures along with YS. CW, ZL, SL, and KL reviewed the manuscript writing. YW supervised the manuscript writing and figure making processes. All authors contributed to the article and approved the submitted version.

\section{FUNDING}

This publication was supported by grants from the National Natural Science Foundation of China (Grant/Award Number: 81570449); Fundamental Research Funds for the Central Universities (Grant/Award Number: GK2020031); and College Students' Innovative and Training Project of Shaanxi Normal University (Grant/Award Number: S202110718230).

aorta from rats fed a high-fat diet: role of aerobic exercise training. Clin. Exp. Pharmacol. Physiol. 45, 293-302. doi: 10.1111/1440-1681.12882

Belo, V. A., Lacchini, R., Miranda, J. A., Lanna, C. M., Souza-Costa, D. C., and Tanus-Santos, J. E. (2015). Increased activity of MMP-2 in hypertensive obese children is associated with hypoadiponectinemia. Obesity 23, 177-182. doi: 10.1002/oby.20939

Boa, B. C. S., Yudkin, J. S., van Hinsbergh, V. W. M., Bouskela, E., and Eringa, E. C. (2017). Exercise effects on perivascular adipose tissue: endocrine and 
paracrine determinants of vascular function. Br. J. Pharmacol. 174, 3466-3481. doi: $10.1111 /$ bph.13732

Brown, I. A. M., Diederich, L., Good, M. E., DeLalio, L. J., Murphy, S. A., CorteseKrott, M. M., et al. (2018). Vascular Smooth Muscle Remodeling in Conductive and Resistance Arteries in Hypertension. Arterioscler. Thromb. Vasc. Biol. 38, 1969-1985. doi: 10.1161/ATVBAHA.118.311229

Castro, M. M., and Tanus-Santos, J. E. (2013). Inhibition of matrix metalloproteinases (MMPs) as a potential strategy to ameliorate hypertensioninduced cardiovascular alterations. Curr. Drug Targets. 14, 335-343. doi: 10.2174/1389450111314030005

Chaulet, H., Desgranges, C., Renault, M. A., Dupuch, F., Ezan, G., Peiretti, F., et al. (2001). Extracellular nucleotides induce arterial smooth muscle cell migration via osteopontin. Circ. Res. 89, 772-778. doi: 10.1161/hh2101.098617

Chen, S., Liu, B., Kong, D., Li, S., Li, C., Wang, H., et al. (2015). Atorvastatin calcium inhibits phenotypic modulation of PDGF-BB-induced VSMCs via down-regulation the Akt signaling pathway. PLoS One 10:e0122577. doi: 10. 1371/journal.pone.0122577

Chi, C., Li, D. J., Jiang, Y. J., Tong, J., Fu, H., Wu, Y. H., et al. (2019). Vascular smooth muscle cell senescence and age-related diseases: state of the art. Biochim. Biophys. Acta Mol. Basis Dis. 1865, 1810-1821. doi: 10.1016/j.bbadis.2018.08. 015

Cyr, A. R., Huckaby, L. V., Shiva, S. S., and Zuckerbraun, B. S. (2020). Nitric Oxide and Endothelial Dysfunction. Crit. Care Clin. 36, 307-321. doi: 10.1016/j.ccc. 2019.12.009

Das, S., Zhang, E., Senapati, P., Amaram, V., Reddy, M. A., Stapleton, K., et al. (2018). A Novel Angiotensin II-Induced Long Noncoding RNA Giver Regulates Oxidative Stress, Inflammation, and Proliferation in Vascular Smooth Muscle Cells. Circ. Res. 123, 1298-1312. doi: 10.1161/CIRCRESAHA.118.313207

Davies, P. F., Remuzzi, A., Gordon, E. J., Dewey, C. F. Jr., and Gimbrone, M. A. Jr. (1986). Turbulent fluid shear stress induces vascular endothelial cell turnover in vitro. Proc. Natl. Acad. Sci. U. S. A. 83, 2114-2117. doi: 10.1073/pnas.83.7. 2114

Diem, G., Brownson, R. C., Grabauskas, V., Shatchkute, A., and Stachenko, S. (2016). Prevention and control of noncommunicable diseases through evidence-based public health: implementing the NCD 2020 action plan. Glob. Health Promot. 23, 5-13. doi: 10.1177/1757975914567513

Escames, G., Ozturk, G., Baño-Otálora, B., Pozo, M. J., Madrid, J. A., Reiter, R. J., et al. (2012). Exercise and melatonin in humans: reciprocal benefits. J. Pineal. Res. 52, 1-11. doi: 10.1111/j.1600-079X.2011.00924.x

Ferreira, A. J., Shenoy, V., Yamazato, Y., Sriramula, S., Francis, J., Yuan, L., et al. (2009). Evidence for angiotensin-converting enzyme 2 as a therapeutic target for the prevention of pulmonary hypertension. Am. J. Respir. Crit. Care Med. 179, 1048-1054. doi: 10.1164/rccm.200811-1678OC

Frantz, E. D. C., Medeiros, R. F., Giori, I. G., Lima, J. B. S., Bento-Bernardes, T., Gaique, T. G., et al. (2017). Exercise training modulates the hepatic reninangiotensin system in fructose-fed rats. Exp. Physiol. 102, 1208-1220. doi: 10. 1113/EP085924

Fu, B., Su, Y., Ma, X., Mu, C., and Yu, F. (2018). Scoparone attenuates angiotensin II-induced extracellular matrix remodeling in cardiac fibroblasts. J. Pharmacol. Sci. 137, 110-115. doi: 10.1016/j.jphs.2018.05.006

Furchgott, R. F., and Zawadzki, J. V. (1980). The obligatory role of endothelial cells in the relaxation of arterial smooth muscle by acetylcholine. Nature 288, 373-376. doi: 10.1038/288373a0

Ghaffari, S., Leask, R. L., and Jones, E. A. (2015). Simultaneous imaging of blood flow dynamics and vascular remodelling during development. Development 142, 4158-4167. doi: 10.1242/dev.127019

Ghantous, C. M., Farhat, R., Djouhri, L., Alashmar, S., Anlar, G., Korashy, H. M., et al. (2020). Molecular Mechanisms of Adiponectin-Induced Attenuation of Mechanical Stretch-Mediated Vascular Remodeling. Oxid. Med. Cell. Longev. 2020:6425782. doi: 10.1155/2020/6425782

Gibbons, G. H., and Dzau, V. J. (1994). The emerging concept of vascular remodeling. N. Engl. J. Med. 330, 1431-1438. doi: 10.1056/ NEJM199405193302008

Gil-Ortega, M., Condezo-Hoyos, L., García-Prieto, C. F., Arribas, S. M., González, M. C., Aranguez, I., et al. (2014). Imbalance between pro and anti-oxidant mechanisms in perivascular adipose tissue aggravates long-term high-fat dietderived endothelial dysfunction. PLoS One 9:e95312. doi: 10.1371/journal.pone. 0095312
Green, D. J. (2009). Exercise training as vascular medicine: direct impacts on the vasculature in humans. Exerc. Sport Sci. Rev. 37, 196-202. doi: 10.1097/JES. 0b013e3181b7b6e3

Green, D. J., Hopman, M. T., Padilla, J., Laughlin, M. H., and Thijssen, D. H. (2017). Vascular Adaptation to Exercise in Humans: role of Hemodynamic Stimuli. Physiol. Rev. 97, 495-528. doi: 10.1152/physrev.00014.2016

Gusan, S., and Anand-Srivastava, M. B. (2013). cAMP attenuates the enhanced expression of Gi proteins and hyperproliferation of vascular smooth muscle cells from SHR: role of ROS and ROS-mediated signaling. Am. J. Physiol. Cell Physiol. 304, C1198-C1209. doi: 10.1152/ajpcell.00269.2012

Hald, E. S., and Alford, P. W. (2014). Smooth muscle phenotype switching in blast traumatic brain injury-induced cerebral vasospasm. Transl. Stroke Res. 5, 385-393. doi: 10.1007/s12975-013-0300-3

Han, B. H., Yoon, J. J., Kim, H. Y., Ahn, Y. M., Jin, S. N., Wen, J. F., et al. (2019). Inhibitory effects of herbal decoction Ojeoksan on proliferation and migration in vascular smooth muscle cells. J. Physiol. Pharmacol. 70, 287-94. doi: 10.26402/jpp.2019.2.12

Hardy, E., Hardy-Sosa, A., and Fernandez-Patron, C. (2018). MMP-2: is too low as bad as too high in the cardiovascular system? Am. J. Physiol. Heart Circ. Physiol. 315, H1332-H1340. doi: 10.1152/ajpheart.00198.2018

He, Y., Hara, H., and Núñez, G. (2016). Mechanism and Regulation of NLRP3 Inflammasome Activation. Trends Biochem. Sci. 41, 1012-1021. doi: 10.1016/ j.tibs.2016.09.002

Hendrickson, R. J., Cappadona, C., Yankah, E. N., Sitzmann, J. V., Cahill, P. A., and Redmond, E. M. (1999). Sustained pulsatile flow regulates endothelial nitric oxide synthase and cyclooxygenase expression in co-cultured vascular endothelial and smooth muscle cells. J. Mol. Cell. Cardiol. 31, 619-629. doi: 10.1006/jmcc.1998.0898

Hua, Y., and Nair, S. (2015). Proteases in cardiometabolic diseases: pathophysiology, molecular mechanisms and clinical applications. Biochim. Biophys. Acta. 1852, 195-208. doi: 10.1016/j.bbadis.2014.04.032

Huang, T., Lu, C., Schumann, M., Le, S., Yang, Y., Zhuang, H., et al. (2018). Timing of Exercise Affects Glycemic Control in Type 2 Diabetes Patients Treated with Metformin. J. Diabetes Res. 2018:2483273. doi: 10.1155/2018/2483273

Ignarro, L. J., Byrns, R. E., Buga, G. M., and Wood, K. S. (1987). Endothelium-derived relaxing factor from pulmonary artery and vein possesses pharmacologic and chemical properties identical to those of nitric oxide radical. Circ. Res. 61, 866-879. doi: 10.1161/01.res.61.6.866

Iwakiri, Y., and Groszmann, R. J. (2007). Vascular endothelial dysfunction in cirrhosis. J. Hepatol. 46, 927-934. doi: 10.1016/j.jhep.2007.02.006

Jiang, H., Lun, Y., Wu, X., Xia, Q., Zhang, X., Xin, S., et al. (2014). Association between the hypomethylation of osteopontin and integrin beta3 promoters and vascular smooth muscle cell phenotype switching in great saphenous varicose veins. Int. J. Mol. Sci. 15, 18747-18761. doi: 10.3390/ijms151018747

Jin, H. Y., Song, B., Oudit, G. Y., Davidge, S. T., Yu, H. M., Jiang, Y. Y., et al. (2012). ACE2 deficiency enhances angiotensin II-mediated aortic profilin-1 expression, inflammation and peroxynitrite production. PLoS One 7:e38502. doi: 10.1371/journal.pone.0038502

Jufri, N. F., Mohamedali, A., Avolio, A., and Baker, M. S. (2015). Mechanical stretch: physiological and pathological implications for human vascular endothelial cells. Vasc. Cell. 7:8. doi: 10.1186/s13221-015-0033-z

Kang, Y., Ding, L., Dai, H., Wang, F., Zhou, H., Gao, Q., et al. (2019). Intermedin in Paraventricular Nucleus Attenuates Ang II-Induced Sympathoexcitation through the Inhibition of NADPH Oxidase-Dependent ROS Generation in Obese Rats with Hypertension. Int. J. Mol. Sci. 20:4217. doi: 10.3390/ ijms20174217

Kawai, T., Forrester, S. J., O’Brien, S., Baggett, A., Rizzo, V., and Eguchi, S. (2017). AT1 receptor signaling pathways in the cardiovascular system. Pharmacol. Res. 125, 4-13. doi: 10.1016/j.phrs.2017.05.008

Kennedy, A. J., Yang, P., Read, C., Kuc, R. E., Yang, L., Taylor, E. J., et al. (2016). Chemerin Elicits Potent Constrictor Actions via Chemokine-Like Receptor 1 (CMKLR1), not G-Protein-Coupled Receptor 1 (GPR1), in Human and Rat Vasculature. J. Am. Heart Assoc. 238, R79-R94. doi: 10.1161/JAHA.116.004421

Konukoglu, D., and Uzun, H. (2017). Endothelial Dysfunction and Hypertension. Adv. Exp. Med. Biol. 856, 511-540. doi: 10.1007/5584_2016_90

Kuchan, M. J., and Frangos, J. A. (1993). Shear stress regulates endothelin-1 release via protein kinase C and cGMP in cultured endothelial cells. Am. J. Physiol. 264, H150-H156. doi: 10.1152/ajpheart.1993.264.1.H150 
Landon, E. J., and Inagami, T. (2005). Beyond the G protein: the saga of the type 2 angiotensin II receptor. Arterioscler. Thromb. Vasc. Biol. 25, 15-16. doi: 10.1161/01.ATV.0000153047.93274.5c

Laughlin, M. H., Newcomer, S. C., and Bender, S. B. (2008). Importance of hemodynamic forces as signals for exercise-induced changes in endothelial cell phenotype. J. Appl. Physiol. 104, 588-600. doi: 10.1152/japplphysiol.01096.2007

Lee, M. Y., and Griendling, K. K. (2008). Redox signaling, vascular function, and hypertension. Antioxid Redox Signal. 10, 1045-1059. doi: 10.1089/ars.2007.1986

Lee, S., Norheim, F., Langleite, T. M., Noreng, H. J., Storås, T. H., Afman, L. A., et al. (2016). Effect of energy restriction and physical exercise intervention on phenotypic flexibility as examined by transcriptomics analyses of mRNA from adipose tissue and whole body magnetic resonance imaging. Physiol. Rep. 4:e13019. doi: 10.14814/phy2.13019

Li, X. C., Zhang, J., and Zhuo, J. L. (2017). The vasoprotective axes of the reninangiotensin system: physiological relevance and therapeutic implications in cardiovascular, hypertensive and kidney diseases. Pharmacol. Res. 125, 21-38. doi: $10.1016 /$ j.phrs.2017.06.005

Lopes, R. A., Neves, K. B., Tostes, R. C., Montezano, A. C., and Touyz, R. M. (2015). Downregulation of Nuclear Factor Erythroid 2-Related Factor and Associated Antioxidant Genes Contributes to Redox-Sensitive Vascular Dysfunction in Hypertension. Hypertension. 66, 1240-1250. doi: 10.1161/ HYPERTENSIONAHA.115.06163

Luo, X., Xiao, Y., Song, F., Yang, Y., Xia, M., and Ling, W. (2012). Increased plasma S-adenosyl-homocysteine levels induce the proliferation and migration of VSMCs through an oxidative stress-ERK1/2 pathway in apoE(-/-) mice. Cardiovasc. Res. 95, 241-250. doi: 10.1093/cvr/cvs130

Ma, B., and Wells, A. (2014). The mitogen-activated protein (MAP) kinases p38 and extracellular signal-regulated kinase (ERK) are involved in hepatocytemediated phenotypic switching in prostate cancer cells. J. Biol. Chem. 289, 11153-11161. doi: 10.1074/jbc.M113.540237

Magnani, F., and Mattevi, A. (2019). Structure and mechanisms of ROS generation by NADPH oxidases. Curr. Opin. Struct. Biol. 59, 91-97. doi: 10.1016/j.sbi.2019. 03.001

Malek, A. M., Greene, A. L., and Izumo, S. (1993). Regulation of endothelin 1 gene by fluid shear stress is transcriptionally mediated and independent of protein kinase C and cAMP. Proc. Natl. Acad. Sci. U. S. A. 90, 5999-6003. doi: $10.1073 /$ pnas.90.13.5999

Mancia, G., De Backer, G., Dominiczak, A., Cifkova, R., Fagard, R., Germano, G., et al. (2007). 2007 Guidelines for the Management of Arterial Hypertension: the Task Force for the Management of Arterial Hypertension of the European Society of Hypertension (ESH) and of the European Society of Cardiology (ESC). J. Hypertens. 25, 1105-1187. doi: 10.1097/HJH.0b013e3281f c975a

Mehta, P. K., and Griendling, K. K. (2007). Angiotensin II cell signaling: physiological and pathological effects in the cardiovascular system. Am. J. Physiol. Cell. Physiol. 292, C82-C97. doi: 10.1152/ajpcell.00287.2006

Mikolajczyk, T. P., Nosalski, R., Skiba, D. S., Koziol, J., Mazur, M., JustoJunior, A. S., et al. (2019). 1,2,3,4,6-Penta-O-galloyl-beta-d-glucose modulates perivascular inflammation and prevents vascular dysfunction in angiotensin II-induced hypertension. Br. J. Pharmacol. 176, 1951-1965. doi: 10.1111/bph. 14583

Miyabe, M., Ohashi, K., Shibata, R., Uemura, Y., Ogura, Y., Yuasa, D., et al. (2014). Muscle-derived follistatin-like 1 functions to reduce neointimal formation after vascular injury. Cardiovasc. Res. 103, 111-120. doi: 10.1093/cvr/cvu105

Monteiro, H. P., Rodrigues, E. G., Amorim Reis, A. K. C., Longo, L. S. Jr., Ogata, F. T., Moretti, A. I. S., et al. (2019). Nitric oxide and interactions with reactive oxygen species in the development of melanoma, breast, and colon cancer: A redox signaling perspective. Nitric. Oxide. 89, 1-13. doi: 10.1016/j.niox.2019.04. 009

Montezano, A. C., Dulak-Lis, M., Tsiropoulou, S., Harvey, A., Briones, A. M., and Touyz, R. M. (2015). Oxidative stress and human hypertension: vascular mechanisms, biomarkers, and novel therapies. Can. J. Cardiol. 31, 631-641. doi: 10.1016/j.cjca.2015.02.008

Moraes-Teixeira Jde, A., Félix, A., Fernandes-Santos, C., Moura, A. S., Mandarimde-Lacerda, C. A., and de Carvalho, J. J. (2010). Exercise training enhances elastin, fibrillin and nitric oxide in the aorta wall of spontaneously hypertensive rats. Exp. Mol. Pathol. 89, 351-357. doi: 10.1016/j.yexmp.2010. 08.004
Nishio, E., and Watanabe, Y. (1997). The involvement of reactive oxygen species and arachidonic acid in alpha 1-adrenoceptor-induced smooth muscle cell proliferation and migration. Br. J. Pharmacol. 121, 665-670. doi: 10.1038/sj.bjp. 0701171

Nosalski, R., and Guzik, T. J. (2017). Perivascular adipose tissue inflammation in vascular disease. Br. J. Pharmacol. 174, 3496-3513. doi: 10.1111/bph.13705

Nowak, K. L., Wang, W., Farmer-Bailey, H., Gitomer, B., Malaczewski, M., Klawitter, J., et al. (2018). Vascular Dysfunction, Oxidative Stress, and Inflammation in Autosomal Dominant Polycystic Kidney Disease. Clin. J. Am. Soc. Nephrol. 13, 1493-1501. doi: 10.2215/CJN.05850518

Owens, G. K., Kumar, M. S., and Wamhoff, B. R. (2004). Molecular regulation of vascular smooth muscle cell differentiation in development and disease. Physiol. Rev. 84, 767-801. doi: 10.1152/physrev.00041.2003

Pagonas, N., Vlatsas, S., Bauer, F., Seibert, F. S., Zidek, W., Babel, N., et al. (2017). Aerobic versus isometric handgrip exercise in hypertension: a randomized controlled trial. J. Hypertens. 35, 2199-2206. doi: 10.1097/HJH. 000000000001445

Passos-Silva, D. G., Verano-Braga, T., and Santos, R. A. (2013). Angiotensin(1-7): beyond the cardio-renal actions. Clin. Sci. 124, 443-456. doi: 10.1042/ CS20120461

Patel, V. B., Bodiga, S., Basu, R., Das, S. K., Wang, W., Wang, Z., et al. (2012). Loss of angiotensin-converting enzyme-2 exacerbates diabetic cardiovascular complications and leads to systolic and vascular dysfunction: a critical role of the angiotensin II/AT1 receptor axis. Circ. Res. 110, 1322-1335. doi: 10.1161/ CIRCRESAHA.112.268029

Prado, A. F., Pernomian, L., Azevedo, A., Costa, R. A. P., Rizzi, E., Ramos, J., et al. (2018). Matrix metalloproteinase-2-induced epidermal growth factor receptor transactivation impairs redox balance in vascular smooth muscle cells and facilitates vascular contraction. Redox. Biol. 18, 181-190. doi: 10.1016/j.redox. 2018.07.005

Qi, J., Yu, X. J., Fu, L. Y., Liu, K. L., Gao, T. T., Tu, J. W., et al. (2019). Exercise Training Attenuates Hypertension Through TLR4/MyD88/NFkappaB Signaling in the Hypothalamic Paraventricular Nucleus. Front. Neurosci. 13:1138. doi: 10.3389/fnins.2019.01138

Ramkhelawon, B., Vilar, J., Rivas, D., Mees, B., de Crom, R., Tedgui, A., et al. (2009). Shear stress regulates angiotensin type 1 receptor expression in endothelial cells. Circ. Res. 105, 869-875. doi: 10.1161/CIRCRESAHA.109.204040

Redmond, E. M., Cahill, P. A., and Sitzmann, J. V. (1998). Flow-mediated regulation of G-protein expression in cocultured vascular smooth muscle and endothelial cells. Arterioscler. Thromb. Vasc. Biol. 18, 75-83. doi: 10.1161/01. atv.18.1.75

Ren, X. S., Tong, Y., Ling, L., Chen, D., Sun, H. J., Zhou, H., et al. (2017). NLRP3 Gene Deletion Attenuates Angiotensin II-Induced Phenotypic Transformation of Vascular Smooth Muscle Cells and Vascular Remodeling. Cell. Physiol. Biochem. 44, 2269-2280. doi: 10.1159/000486061

Rodrigues Prestes, T. R., Rocha, N. P., Miranda, A. S., Teixeira, A. L., and Simoes-ESilva, A. C. (2017). The Anti-Inflammatory Potential of ACE2/Angiotensin-(17)/Mas Receptor Axis: evidence from Basic and Clinical Research. Curr. Drug Targets 18, 1301-1313. doi: 10.2174/1389450117666160727142401

Rubanyi, G. M., Romero, J. C., and Vanhoutte, P. M. (1986). Flow-induced release of endothelium-derived relaxing factor. Am. J. Physiol. 250, H1145-H1149. doi: 10.1152/ajpheart.1986.250.6.H1145

Ruegsegger, G. N., and Booth, F. W. (2018). Health Benefits of Exercise. Cold Spring Harb Perspect. Med. 8:a029694. doi: 10.1101/cshperspect.a029694

Santos, R. A. S., Sampaio, W. O., Alzamora, A. C., Motta-Santos, D., Alenina, N., Bader, M., et al. (2018). The ACE2/Angiotensin-(1-7)/MAS Axis of the ReninAngiotensin System: focus on Angiotensin-(1-7). Physiol. Rev. 98, 505-553. doi: $10.1152 /$ physrev.00023.2016

Saxton, S. N., Withers, S. B., Nyvad, J., Mazur, A., Matchkov, V., Heagerty, A. M., et al. (2019). Perivascular Adipose Tissue Contributes to the Modulation of Vascular Tone in vivo. J. Vasc. Res. 56:6. doi: 10.1159/000502689

Schiffrin, E. L. (2012). Vascular remodeling in hypertension: mechanisms and treatment. Hypertension 59, 367-374. doi: 10.1161/HYPERTENSIONAHA.111. 187021

Schiffrin, E. L., and Touyz, R. M. (2004). From bedside to bench to bedside: role of renin-angiotensin-aldosterone system in remodeling of resistance arteries in hypertension. Am. J. Physiol. Heart Circ. Physiol. 287, H435-H446. doi: 10.1152/ajpheart.00262.2004 
Schlich, R., Willems, M., Greulich, S., Ruppe, F., Knoefel, W. T., Ouwens, D. M., et al. (2013). VEGF in the crosstalk between human adipocytes and smooth muscle cells: depot-specific release from visceral and perivascular adipose tissue. Med. Inflamm. 13:982458. doi: 10.1155/2013/982458

Seo, K. W., Lee, S. J., Ye, B. H., Kim, Y. W., Bae, S. S., and Kim, C. D. (2015). Mechanical stretch enhances the expression and activity of osteopontin and MMP-2 via the Akt1/AP-1 pathways in VSMC. J. Mol. Cell. Cardiol. 85, 13-24. doi: 10.1016/j.yjmcc.2015.05.006

Shu, X., Ruddiman, C. A., Keller, T. C. S. IV, Keller, A. S., Yang, Y., Good, M. E., et al. (2019). Heterocellular Contact Can Dictate Arterial Function. Circ. Res. 124, 1473-1481. doi: 10.1161/CIRCRESAHA.118.313926

Slaats, J., Ten Oever, J., van de Veerdonk, F. L., and Netea, M. G. (2016). IL-1beta/IL-6/CRP and IL-18/ferritin: distinct Inflammatory Programs in Infections. PLoS Pathog. 12:e1005973. doi: 10.1371/journal.ppat.1005973

Somanna, N. K., Valente, A. J., Krenz, M., Fay, W. P., Delafontaine, P., and Chandrasekar, B. (2016). The Nox1/4 Dual Inhibitor GKT137831 or Nox4 Knockdown Inhibits Angiotensin-II-Induced Adult Mouse Cardiac Fibroblast Proliferation and Migration. AT1 Physically Associates With Nox4. J. Cell. Physiol. 231, 1130-1141. doi: 10.1002/jcp.25210

Sousa, A. S., Sponton, A. C. S., Trifone, C. B., and Delbin, M. A. (2019). Aerobic Exercise Training Prevents Perivascular Adipose Tissue-Induced Endothelial Dysfunction in Thoracic Aorta of Obese Mice. Front. Physiol. 10:1009. doi: 10.3389/fphys.2019.01009

Speer, M. Y., McKee, M. D., Guldberg, R. E., Liaw, L., Yang, H. Y., Tung, E., et al. (2002). Inactivation of the osteopontin gene enhances vascular calcification of matrix Gla protein-deficient mice: evidence for osteopontin as an inducible inhibitor of vascular calcification in vivo. J. Exp. Med. 196, 1047-1055. doi: 10.1084/jem.20020911

Sponton, A. C., Silva, F. H., Araujo, H. N., Valgas da Silva, C. P., de Moraes, C., Antunes, E., et al. (2017). Circulating Concentrations of Adipocytokines and Their Receptors in the Isolated Corpus Cavernosum and Femoral Artery from Trained Rats on a High-Fat Diet. J. Vasc. Res. 54, 33-50. doi: 10.1159/000457800

Straub, A. C., Butcher, J. T., Billaud, M., Mutchler, S. M., Artamonov, M. V., Nguyen, A. T., et al. (2014). Hemoglobin alpha/eNOS coupling at myoendothelial junctions is required for nitric oxide scavenging during vasoconstriction. Arterioscler. Thromb. Vasc. Biol. 34, 2594-2600. doi: 10.1161/ ATVBAHA.114.303974

Straub, A. C., Lohman, A. W., Billaud, M., Johnstone, S. R., Dwyer, S. T., Lee, M. Y., et al. (2012). Endothelial cell expression of haemoglobin alpha regulates nitric oxide signalling. Nature 491, 473-477. doi: 10.1038/nature11626

Strawn, W. B., Ferrario, C. M., and Tallant, E. A. (1999). Angiotensin-(1-7) reduces smooth muscle growth after vascular injury. Hypertension 33, 207-211. doi: 10.1161/01.hyp.33.1.207

Sun, H. J., Ren, X. S., Xiong, X. Q., Chen, Y. Z., Zhao, M. X., Wang, J. J., et al. (2017). NLRP3 inflammasome activation contributes to VSMC phenotypic transformation and proliferation in hypertension. Cell. Death Dis 8:e3074. doi: 10.1038/cddis.2017.470

Suvorava, T., and Cortese-Krott, M. M. (2018). Exercise-Induced Cardioprotection via eNOS: a Putative Role of Red Blood Cell Signaling. Curr. Med. Chem. 25, 4457-4474. doi: 10.2174/0929867325666180307112557

Thomas, M. C., Burns, W. C., and Cooper, M. E. (2005). Tubular changes in early diabetic nephropathy. Adv. Chronic. Kidney Dis. 12, 177-186. doi: 10.1053/j. ackd.2005.01.008

Touyz, R. M., Alves-Lopes, R., Rios, F. J., Camargo, L. L., Anagnostopoulou, A., Arner, A., et al. (2018). Vascular smooth muscle contraction in hypertension. Cardiovasc. Res. 114, 529-539. doi: 10.1093/cvr/cvy023

Vasa, M., Fichtlscherer, S., Aicher, A., Adler, K., Urbich, C., Martin, H., et al. (2001). Number and migratory activity of circulating endothelial progenitor cells inversely correlate with risk factors for coronary artery disease. Circ. Res 89, E1-E7. doi: 10.1161/hh1301.093953

Virdis, A., Bacca, A., Colucci, R., Duranti, E., Fornai, M., Materazzi, G., et al. (2013). Endothelial dysfunction in small arteries of essential hypertensive patients: role of cyclooxygenase-2 in oxidative stress generation. Hypertension 62, 337-344. doi: 10.1161/HYPERTENSIONAHA.111.00995

Virdis, V., Emiliano Di, Chiara, R., Umberto, D. A., Eleonora, S., Marco, A., et al. (2015). Tumour necrosis factor-alpha participates on the endothelin-1/nitric oxide imbalance in small arteries from obese patients: role of perivascular adipose tissue. Eur. Heart J. 36, 784-794. doi: 10.1093/eurheartj/ehu072

Wang, X., and Khalil, R. A. (2018). Matrix Metalloproteinases, Vascular Remodeling, and Vascular Disease. Adv. Pharmacol. 81, 241-330. doi: 10.1016/ bs.apha.2017.08.002

Ye, S., Sun, Y., Bie, A., Zhou, Y., Liu, J., and Liu, Q. (2009). Influence of osteopontin short hairpin RNA on the proliferation and activity of rat vascular smooth muscle cells. J. Huazhong. Univ. Sci. Technol. Med. Sci. 29, 144-149. doi: 10. 1007/s11596-009-0202-5

You, T., Arsenis, N. C., Disanzo, B. L., and Lamonte, M. J. (2013). Effects of exercise training on chronic inflammation in obesity: current evidence and potential mechanisms. Sports Med. 43, 243-256. doi: 10.1007/s40279-013-0023-3

Yue, J., Chang, S., Xiao, Z., Qi, Y., and He, J. (2018). The protective effect of puerarin on angiotensin II-induced aortic aneurysm formation by the inhibition of NADPH oxidase activation and oxidative stress-triggered AP1 signaling pathways. Oncol. Lett. 16, 3327-3332. doi: 10.3892/ol.2018. 9021

Zhang, H., Han, G. W., Batyuk, A., Ishchenko, A., White, K. L., Patel, N., et al. (2017). Structural basis for selectivity and diversity in angiotensin II receptors. Nature 544, 327-332. doi: 10.1038/nature22035

Zhang, L., Zhang, Y., Wu, Y., Yu, J., Zhang, Y., Zeng, F., et al. (2019). Role of the Balance of Akt and MAPK Pathways in the Exercise-Regulated Phenotype Switching in Spontaneously Hypertensive Rats. Int. J. Mol. Sci. 20:5690. doi: $10.3390 /$ ijms 20225690

Zhang, L., Zheng, H., Luo, J., Li, L., Pan, X., Jiang, T., et al. (2018). Inhibition of endothelial nitric oxide synthase reverses the effect of exercise on improving cognitive function in hypertensive rats. Hypertens Res. 41, 414-425. doi: 10. 1038/s41440-018-0033-5

Zhang, R., Wu, Y., Zhao, M., Liu, C., Zhou, L., Shen, S., et al. (2009). Role of HIF-1alpha in the regulation ACE and ACE2 expression in hypoxic human pulmonary artery smooth muscle cells. Am. J. Physiol. Lung Cell. Mol. Physiol. 297, L631-L640. doi: 10.1152/ajplung.90415.2008

Zhang, Y., Yu, X. J., Chen, W. S., Gao, H. L., Liu, K. L., Shi, X. L., et al. (2016). Exercise training attenuates renovascular hypertension partly via RAS- ROSglutamate pathway in the hypothalamic paraventricular nucleus. Sci. Rep. 6, 37467. doi: 10.1038/srep37467

Zhao, Y., Vanhoutte, P. M., and Leung, S. W. (2015). Vascular nitric oxide: beyond eNOS. J. Pharmacol. Sci. 129, 83-94. doi: 10.1016/j.jphs.2015.09.002

Zhong, J., Basu, R., Guo, D., Chow, F. L., Byrns, S., Schuster, M., et al. (2010). Angiotensin-converting enzyme 2 suppresses pathological hypertrophy, myocardial fibrosis, and cardiac dysfunction. Circulation 128, 717-28,18following728. doi: 10.1161/CIRCULATIONAHA.110.955369

Zhong, J., Guo, D., Chen, C. B., Wang, W., Schuster, M., Loibner, H., et al. (2011). Prevention of angiotensin II-mediated renal oxidative stress, inflammation, and fibrosis by angiotensin-converting enzyme 2. Hypertension 57, 314-322. doi: 10.1161/HYPERTENSIONAHA.110.164244

Zhou, J., Li, Y. S., and Chien, S. (2014). Shear stress-initiated signaling and its regulation of endothelial function. Arterioscler. Thromb. Vasc. Biol. 34, 2191-2198. doi: 10.1161/ATVBAHA.114.303422

Conflict of Interest: The authors declare that the research was conducted in the absence of any commercial or financial relationships that could be construed as a potential conflict of interest.

Publisher's Note: All claims expressed in this article are solely those of the authors and do not necessarily represent those of their affiliated organizations, or those of the publisher, the editors and the reviewers. Any product that may be evaluated in this article, or claim that may be made by its manufacturer, is not guaranteed or endorsed by the publisher.

Copyright (c) 2022 Song, Jia, Hua, Wu, Li, Li, Liang and Wang. This is an open-access article distributed under the terms of the Creative Commons Attribution License (CC BY). The use, distribution or reproduction in other forums is permitted, provided the original author(s) and the copyright owner(s) are credited and that the original publication in this journal is cited, in accordance with accepted academic practice. No use, distribution or reproduction is permitted which does not comply with these terms. 